\title{
Spectrophotometeric Determination of Bromate in Bread by the Oxidation of Dyes
}

\section{*1'OJEKA E O; ${ }^{2}$ OBIDIAKU MC; ${ }^{1}$ ENUKORAH, C}

\author{
${ }^{1}$ Department of Applied Science, C.S.T, Kaduna Polytechnic P.M.B 20, Kaduna, Nigeria
}

${ }^{2}$ K.aduna Refinrery and Petrochemical Company Limited, Kaduna, Nigeria

\begin{abstract}
A spectrophotometric method for the determination of bromate based on the oxidation of congo red and crystal violet dyes in a hydrochloric acid medium is described. The bromate level in bread samples determined range from $3.70 \mu \mathrm{g} \mathrm{g^{-1 }}$ to $12.10 \mu \mathrm{g} \mathrm{g}^{-1}$; with limits of quantification of $0.45-0.78 \mu \mathrm{g} \mathrm{g}^{-1}$. Results show the presence of detectable residue levels of potassium bromate in all the bread samples analysed and the results compare favourably with established AOAC method. @@JASEM
\end{abstract}

Bread is food baked from mixed yeast leavened dough obtained from flour and bromated or phosphate flour or their combination in the presence of Sacharomyces cerevisae yeast and $1 \%$ bread bean flour. The bean flour activates the whitening of the dough, improves the quality of the bread, and increases lipoxygenase, which produces hydroperoxide, an oxidising agent. Ascorbic acid dissolved in water is also added to the dough mixture to improve the gluten content (de Man, 1990; Alias and Linden, 1999). Small amount of oxidising agents such as potassium bromate, potassium iodate, and calcium peroxide are added to flour to enhance the maturing process and baking. The bromate voluminises the centre of the bread (produced from low protein wheat), and increases the size of the bread artificially; as well as producing bread with a pure crumb structure (de Man, 1990). The presence of bromate in bread may cause renal failure, respiratory depression, hearing loss, breakdown of vitamins and cancer to humans (IPCS, 1994; Field, 2004).

Atkins (1993) analysed bromate in bread by gas chromatography (GC) based on the formation of a volatile derivative of bromate and obtained a limit of $12 \mu \mathrm{g} \mathrm{kg}^{-1}$. Dennis (1994) used inductively coupled plasma -mass spectrometry and obtained a higher C.V of $18 \%$ compared to $12 \%$ when G.C was used, while Fuller and Ottaway (1970) reported a kinetic study of bordeaux oxidation and reported that the rate of reaction was dependent on Bordeaux concentration. Medina-Escriche et al (1985) determined bromate by the oxidation of pyrogallol red dye in a sulphuric acid medium and obtained bromate in the range $0.0-3.08 \times 10^{-5} \mathrm{~mol} \mathrm{dm}^{-3}$. Prior to their work, a kinetic-spectrophotometric determination of bromate by the oxidation of dyes has not been described. While some of these methods are time-consuming, satisfactory results were not obtained on applying the method of Medina Escriche et al (1985) to bread samples. The aim of the present study is to modify and highlight the use of dyestuffs in the detremination of bromate in bread samples as a viable routine method based on the work of Medina - Escriche et al (1985). The described method involves a simple and readily available instrumentation which is an advantage to a developing country like Nigeria.

\section{MATERIALS AND METHODS}

Apparatus: Absorbance measurements were made with a Compec Visible Spectrophotometer Model 201 at $\lambda_{\max }$ of $485 \mathrm{~nm}$ for samples containing crystal violet and $452 \mathrm{~nm}$ for samples containing Congo red organic reagents respectively. All measurements were made at room temperature against water as reference.

Reagents: All reagents were of analytical grade unless otherwise specified. $2 \mathrm{M} \mathrm{HCl}: 43.10 \mathrm{~cm}^{3}$ of concentrated $\mathrm{Hcl}$ was diluted with water in a $250 \mathrm{~cm}^{3}$ volumetric flask and made up to mark with distilled water. $5 \times 10^{-4} \mathrm{~mol} / \mathrm{dm}^{3}$ Congo red dye solution: $0.348 \mathrm{~g}$ of Congo red (m.wt 696.67) was weighed into a $1000 \mathrm{~cm}^{3}$ volumetric flask, dissolved and diluted to mark with distilled water. $5 \times 10^{-4} \mathrm{~mol} / \mathrm{dm}^{3}$ Crystal Violet dye solution: $0.216 \mathrm{~g}$ of Crystal violet (mwt. 431) was weighed into a $1000 \mathrm{~cm}^{3}$ volumetric flask, dissolved and diluted with distilled water to mark. Foreign ion solution: Solutions of diverse ions including EDTA, citrates, halides, ascorbic acid and others were prepared by dissolving the calculated amount of each compound to give concentrations of $10-100 \mu \mathrm{g}^{-1}$ and $100 \mathrm{mg} / \mathrm{g}$ of the particular ion. $2.5 \mathrm{x}$ $10^{-3} \mathrm{~mol} \mathrm{dm}^{-3}$ potassium bromate: $4.3 \mathrm{~g}$ of potassium bromate (m.wt 167) was weighed into a $1000 \mathrm{~cm}^{3}$ volumetric flask, dissolved and diluted with distilled water to mark. The working standard solutions were 
prepared in the range, $12,24,36,48,60$ and $72 \mathrm{ppm}$ respectively

Sampling: Bread samples were bought from different retail outlets and bakeries in Kaduna State. Representative samples were bought from south, north, central, western and eastern parts of Kaduna metropolis. Basis for sample selection: The samples analyzed were the most common on popular demand in the respective locations. The bread samples include; Baabsalam (Tudun Nupawa, Kaduna west), Beta Bread (Makera, Kaduna south), Central Bread (Kaduna north), Unity Bread (Narayi, Kaduna East) and Karamah Bread (Ungwan Dosa, Kaduna west).

Sample pretreatment: A circular sample of $2 \mathrm{~cm}$ in diameter from the center of a $15-\mathrm{mm}$ thick slice of each bread sample was taken and dried in an oven for 72 hours at $55^{\circ} \mathrm{C}$. The crust was ground to a fine powder with mortar and pestle. $5 \mathrm{~g}$ of each powdered sample was weighed into a clean $250 \mathrm{~cm}^{3}$ beaker and $50 \mathrm{~cm}^{3}$ of distilled water was added. The mixture was centrifuged and the liquid fraction was diluted to 100 $\mathrm{cm}^{3}$ in a calibrated flask. The appropriate volume of the aliquot was taken for treatment under the proposed procedure. The pretreatment of samples was done in triplicates according to reported method Garcia Sanchez et al (1989).

Proposed procedure: $4 \mathrm{~cm}^{3}$ of aliquot of each of the five bread samples was measured into 10 separate 25 $\mathrm{cm}^{3}$ calibrated flasks. $5 \mathrm{~cm}^{3}$ of $5 \times 10^{-4} \mathrm{~mol} / \mathrm{dm}^{3}$ solution of Congo red dye or $5 \mathrm{~cm}^{3} 5 \times 10^{-4} \mathrm{~mol} / \mathrm{dm}^{-3}$ solution of crystal violet dye was added, followed by $10 \mathrm{~cm}^{3}$ of $2 \mathrm{M} \mathrm{HCl}$ solution. Each flask was diluted to $25-\mathrm{cm}^{3}$ marks with distilled water; and shaken gently prior to colorimetric analysis.

Comparison with Established AOAC Method: Bromates can be detected by pouring over a slab of compressed and wetted flour, a solution containing 0.5 percent potassium iodide in $2 \mathrm{M} \mathrm{HCl}$. Black spots suggest the presence of bromate. An iodometric titration method for bromate determination described by Armstrong (1952) and recommended by the AOAC was applied for this work .

Statistical Analysis: The sensitivities of the two methods, the limits of detection and quantification as well as, precision and accuracy are reported according to modified methods (IUPAC, 1978; ACS, 1980). The analytical sensitivity(s),

$S=\frac{S_{d}}{m}$ where $\mathrm{S}_{\mathrm{d}}=$ standard deviation of the analytical signal; $\mathrm{m}=$ slope of the calibration graph (in absorbance units per $\mu \mathrm{g}$ bromate per $\mathrm{cm}^{3}$ ).

The limit of detection $(\mathrm{LOD})=\frac{3 s}{m}$

The limit of quantification $(\mathrm{LOQ})=\frac{10 S_{r}}{m}$

Where $S_{\mathrm{r}}=$ relative standard deviation of the blank signal: $\mathrm{m}=$ slope of the Calibration graph: and $\mathrm{S}_{\mathrm{r}}=$ $\mathrm{S}_{\mathrm{d}}$ at the detection limit

$$
\text { Relative Error }=\frac{100 \mathrm{t} \mathrm{s}}{\overline{\mathrm{x} \mathrm{n}}}
$$

Where, $\mathrm{t}=$ student $\mathrm{t}$-test; $\mathrm{S}=$ analytical sensitivity; $\bar{x}$ $=$ average value; and $\mathrm{n}=$ number of determinations

Selectivity and Recovery Studies: Varying amounts of potassium bromate were taken in a $50 \mathrm{~cm}^{3}$ calibration flask. Foreign ions were added (cations as sulphate or nitrate salts) and dissolved with $10 \mathrm{~cm}^{3}$ portions of distilled water. $2 \mathrm{~cm}^{3} 5 \times 10^{-4} \mathrm{~mol} \mathrm{dm}^{-3}$ crystal violet dye solution was added followed by $2 \mathrm{~cm}^{3}$ of $2 \mathrm{M}$ hydrochloric acid solution with gentle shaking. The amount of bromate (or foreign ion) was read at 485 $\mathrm{nm}$ directly in concentration units with reference to a solution containing no bromate.

\section{RESULTS AND DISCUSSION}

The use of potassium bromate in flour milling and baking was banned in Nigeria by National Agency for Food, Drug Administration and Control (NAFDAC) in 1993; and its use infringes on the drug and related products (registration) decree 20 of 1999 and NAFDAC Decree 15 of 1993 (Akunyili, 2004).

Joint FAO/WHO (1992) committee's initial recommendation of acceptable level of 0 to $60 \mathrm{mg}$ $\mathrm{KBrO}_{3} / \mathrm{kg}$ flour was withdrawn because long term toxicity and carcinogenicity studies in vitro and in vivo revealed renal cell tumours in hamsters. Also, toxitcity studies showed that potassium bromate affects the nutritional quality of bread by degrading vitamins $\mathrm{A} 1, \mathrm{~B} 1, \mathrm{~B} 2, \mathrm{E}$ and niacin - the main vitamins in bread (FAO/WHO, 1992; PCHRD.com, 2000).

Table 1: Concentration of potassium bromate in bread samples $(\mu \mathrm{g} / \mathrm{g})$

\begin{tabular}{lllr}
\hline Bread & Concentration in $\mu \mathrm{gg}^{-1}$ & Concentration in \\
sample & $\begin{array}{l}\text { at } 452 \mathrm{~nm} \text { congo red } \\
\text { method }\end{array}$ & $\begin{array}{l}\mu g^{-1} \text { at } 485 \mathrm{~nm} \\
\text { crystal violet dye } \\
\end{array}$ & method \\
\hline
\end{tabular}




\begin{tabular}{lll}
\hline $\mathrm{A}$ & $3.70 \pm 0.01$ & $11.60 \pm 0.01$ \\
$\mathrm{~B}$ & $4.20 \pm 0.01$ & $12.00 \pm 0.02$ \\
$\mathrm{C}$ & $4.60 \pm 0.02$ & $11.50 \pm 0.03$ \\
$\mathrm{D}$ & $4.00 \pm 0.01$ & $12.10 \pm 0.01$ \\
$\mathrm{E}$ & $5.20 \pm 0.02$ & $12.10 \pm 0.01$ \\
\hline
\end{tabular}

Table 2: concentration of potassium bromate in bread samples $(\mu \mathrm{g} / \mathrm{g})$ by the AOAC established method

\begin{tabular}{ll}
\hline Bread sample & $\mu \mathrm{g} / \mathrm{g}^{-}$Bromate found \\
\hline A & $12.00 \pm 0.01$ \\
B & $12.35 \pm 0.00$ \\
C & $11.00 \pm 0.02$ \\
D & $12.60 \pm 0.00$ \\
E & $12.00 \pm 0.03$ \\
\hline
\end{tabular}

The oxidation of the dyes by bromate was carried out in a hydrochloric acid medium in which bromate is a strong oxidant.

$$
\mathrm{BrO}_{3}^{-}+6 \mathrm{H}^{+}+6 \underset{\rightleftharpoons}{\rightleftharpoons} \mathrm{Br}^{-}+3 \mathrm{H}_{2} \mathrm{O} \text {....(5) }
$$

With irreversible oxidation indicators, the quantity of bromate solution consumed by the dyestuff indicator is exceedingly small and the indicator is bleached in the presence of $2 \mathrm{M} \mathrm{HCl}$ used for this work:

$$
10 \mathrm{Cl}^{-}+2 \mathrm{BrO}_{3}^{-}+12 \mathrm{H}^{+}=5 \mathrm{Cl}_{2}+\mathrm{Br}_{2}+6 \mathrm{H}_{2} \mathrm{O} . \text {.(6) }
$$

In the presence of hydrochloric acid, the red colour of congo red (a disazo dye) changed to blue. The deepening of the colour has been attributed to resonance among charged canonical structures. Crystal violet is a triarylmethane dye. It is a leuco compound (colourless) converted to tertiary alcohol (colour base) on oxidation. In the presence of acid the colourless benzenoid form changed to the quinonoid dye due to salt formation. The salt is easily reconverted into the leuco - base (Finar, 1973):

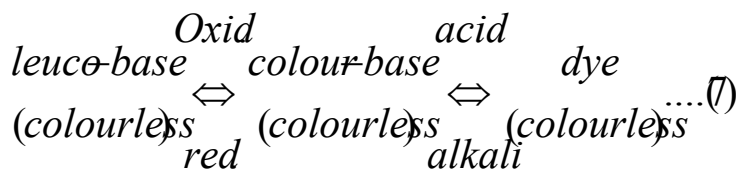

It is purple in weakly acid solution, green in strong acid solution and finally yellow. The colour changes may be adduced in the light of proton addition (Finar, 1973). Both dyes were water soluble because of the two sulpuric acid groups $\left(\mathrm{SO}_{3} \mathrm{H}\right)$ in congo red and dimethylamino groups in crystal violet dye.

The molar absorptivity of congo dye is $9.04 \times 10^{4} \mathrm{dm}^{3} \mathrm{~mol}^{-}$ ${ }^{1} \mathrm{~cm}^{-1}$ at $\lambda_{\max } 452 \mathrm{~nm}$; its wavelength of maximum absorption, while the molar absorptivity of congo crystal violet dye is $9.70 \times 10^{5} \mathrm{dm}^{3} \mathrm{~mol}^{-1} \mathrm{~cm}^{-1}$ at $\lambda_{\max }, 485 \mathrm{~nm}$. The proposed crystal violet method is superior to congo red and recovery method in Table 5 is satisfactory.

Preliminary investigations show that Beer's law was obeyed over the linear dynamic range (LDR) $0.45{\mu \mathrm{gg}^{-1}}^{-}$ $5.50 \mathrm{\mu gg}^{-1}$, and the initial reaction rate was found to be a linear function of the bromate concentration over this range for the two methods. Three determinations were made on each level of bromate concentration to obtain an average reading \pm standard deviation. Results show that the reaction of bromate with the dyes is most sensitive with least slope of the calibration graphs

Table 3; Evaluation of Analytical parameters of the proposed methods

\begin{tabular}{llllllll}
\hline Analytical-mode & Slope $(\mathrm{m})$ & Sensitivity $\left(\mu \mathrm{gg}^{-1}\right)$ & $\begin{array}{l}\mathrm{LOD} \\
\left(\mu \mathrm{gg}^{-1}\right)\end{array}$ & $\begin{array}{l}\text { LOQ } \\
\left(\mu \mathrm{gg}^{-1}\right)\end{array}$ & $\begin{array}{l}\text { LDR } \\
\left(\mu g^{-1}\right)\end{array}$ & $\begin{array}{l}\text { Error } \\
(\%)\end{array}$ & $\begin{array}{l}\text { RSD } \\
(\%)\end{array}$ \\
\hline Crystal violet method & 0.28 & 0.052 & 0.68 & 0.45 & $0.45-5.50$ & 1.50 & 3.75 \\
Congo red method & 1.24 & 0.013 & 0.45 & 0.78 & $0.78-4.80$ & 6.30 & 8.93 \\
\hline
\end{tabular}

Table 4: Selectivity study to estimate the tolerance limit of diverse ions in the presence of $100 \mu \mathrm{g}$ bromate

$\begin{array}{lc}\text { Foreign ion added } & \begin{array}{c}\text { Concentration of } \\ \text { in tolerated in } \mu \mathrm{g}\end{array} \\ \text { in } \mu \mathrm{g} & 100 \\ \text { EDTA; } \mathrm{SO}_{4}{ }^{2-} & 10 \\ \text { Citrate/ tartrate } & 5 \\ \text { Ascorbic acid } & 3 \\ \mathrm{CN}^{-}, \mathrm{Br}^{-} & 2 \\ \mathrm{Fe}^{3+}, \mathrm{Mn}^{7+} & 100 \\ \mathrm{Cu}^{2+} ; \mathrm{Zn}^{2+}, \mathrm{Mn}^{2+} & \end{array}$

The crystal violet proposed procedure has a higher sensitive and lower limits of detection and quantification respectively than the congo red method. Application of the F-test indicates significant variation in the precision of the two methods; the congo red method being the more precise (Tables 1 and 3).Ions such as EDTA, and sulphate do not interfere but cations like iron (III) and manganese (II) which form strong complexes with crystal violet dye even in the acidic medium interfere seriously and similarly, reductants such as bromide, cyanide and ascorbic acid respectively. A maximum error of $2 \%$ in the absorbance reading was considered tolerable. The effect of each ion largely depend on the $\mathrm{pH}$ of the solution and at high $\mathrm{pH}$, the solutions were not affected the same way. The reductants as well as $\mathrm{Fe}(\mathrm{III})$ and $\mathrm{Mn}$ (VI) accelerate the oxidation of crystal violet by bromate while $\mathrm{Cu}$ (II), $\mathrm{Zn}$ (II) and $\mathrm{Mn}(\mathrm{II})$ inhibit the oxidation of the dye by bromate. 
In Table 5, the proposed method using crystal violet dye is superior to the use of congo red, and it (crystal violet) was applied to the determination of potassium bromate in spiked bread samples. The standard addition method was done to reduce matrix effects, ascertain the effectiveness of the proposed method and as a final test of the method. It therefore provides estimates of the content of bromate in bread, and confirmed by the AOAC established method

Table 5: Determination of bromate in bread by standard addition method

\begin{tabular}{llllll}
\hline Bread & Bromate & Bromate & Bromate & Endogeneous & Recovery \\
\hline Sample & $\begin{array}{l}\text { Present } \\
\left(\mu \mathrm{gg}^{-1}\right)\end{array}$ & $\begin{array}{l}\text { Added } \\
\left(\mu \mathrm{gg}^{-1}\right)\end{array}$ & $\begin{array}{l}\text { Found } \\
\left(\mu \mathrm{gg}^{-1}\right)\end{array}$ & $\begin{array}{l}\text { Bromate } \\
\left(\mu \mathrm{gg}^{-1}\right)\end{array}$ & $(\%)$ \\
$\mathrm{A}$ & - & - & $11.60 \pm 0.01$ & 11.60 & - \\
& $11.60 \pm 0.01$ & 3.50 & $15.00 \pm 0.01$ & 0.10 & 99.33 \\
$\mathrm{~B}$ & - & - & $12.00 \pm 0.25$ & 12.00 & - \\
& $12.00 \pm 0.25$ & 4.50 & $16.20 \pm 0.35$ & 0.30 & 98.18 \\
$\mathrm{C}$ & - & - & $11.50 \pm 0.03$ & 11.50 & - \\
& $11.50 \pm 0.03$ & 5.00 & $16.00 \pm 0,01$ & 0.50 & 96.96 \\
$\mathrm{D}$ & - & - & $12.10 \pm 0.01$ & 12.10 & - \\
& $12.10 \pm 0.01$ & 5.50 & $17.34 \pm 0.11$ & 0.26 & 98.52 \\
$\mathrm{E}$ & - & - & $12.10 \pm 0.01$ & 12.10 & - \\
& $12.10 \pm 0.01$ & 6.00 & $18.10 \pm 0.36$ & 0.10 & 100.55 \\
\hline
\end{tabular}

Conclusion: Potassium bromate is a mutagen and has shown the potential to cause cancer. The presence of detectable residue levels of potassium bromate in bread is therefore undersirable considering the long term effect; although the average literature value of bromate in bread is $381.25 \mu \mathrm{gg}^{-1}$. The simplicity of the procedure adopted herein and the good agreement between our result and the standard AOAC method further recommends our method for consideration in routine bread analysis for bromate. Millers and bakers should be encouraged to comply with set standards of Good Manufacturing Practice (GMP) and Hazard Analysis Critical Control Points (HACCP) guidelines acceptable world wide. In addition, they should explore such other natural bread improvers like AMIPAN and unbrominated bread improver, SS103U made in Malaysia.

\section{REFERENCES}

Akunyili, D N (2004). Medical Nigeria: Potassium bromate in bread... what are the implications.? Sensitization and Interactive workshop for flour millers and bakers. Vanguard Media Limited Online.

Alias, C and Linden, G (1999). Food Biochemistry, Aspen publishers Inc. Gaithersburg, Maryland. Pp 125-29.

American Chemical Society (ACS) (1980). Committee on Environmental Improvement. Anal. Chem. Vol.52, Pp 2242-2244.

Armstrong, A W (1952). Analyst vol. 77 pp 460-4.

Atkins, D P (1993). MAFF UK - Potassium Bromate in Bread. Joint Food Safety and Standards Group. Food surveillance information sheet. Number 2.

de Man, M J (1990). Principles of Food Chemistry, Second Edition. Van Nostrand, Reinhold, New York. Pp $441-$ 443.

Dennis, M J (1994). "The determination of flour imporver potassium bromate in bread by gas chromatographic and
ICP-MS methods." Food Additives and contaminants: Vol 11. No. 6. Pp 633-9.

Field, Q S (2004). Ingredients: Potassium bromate; Chemical formula, Synonyms, Prescription and Uses. The Breadery .com.

Finar, I L (1973). Organic Chemistry Vol. I. The fundamental Principles. $6^{\text {th }}$ Edition, The English Language Book Society and Longman Group Ltd, London Pp 884-887.

Fuller, W; Ottawy, J M (1970). An Analytical and Kinetic Investigation of the Vanadium (V)-catalyzed Bromate oxidation of Bordeaux. Analyst, Vol 95; Pp28 -31.

Garcia Sanchez, F; Navas Diaz A; Santiago Navas, M (1989). Photometric and fluorometric methods for the Determination of Bromate in Bread Analyst Vol. 114. Pp 743-745.

IPCS, (1994). International Programme on Chemical Safety and the Commission of the European Communities (CEC): Potassium Bromate.

IUPAC, (1978).Compendium of Analytical Nomenclature. Pergamon press, Oxford.pp10-15.

Joint FAO/WHO, (1992). Expert Committee on Food Additives. Evaluation of certain food additives and contaminants. Geneva, World Health Organization Pp. 25-30.

Medina-Escriche, J; Devillano-Cabeza, A; Martin-Panella M; Liobat- Estelles, M; (1985). Spectrophotometric Determination of Bromate by oxidation of Pyragallol Red, Analyst, Vol. 110 Pp 1467-1471.

PCHRD. Com, (2000). Health Issues; Philippine Council for Health Research and Development: Archives. 